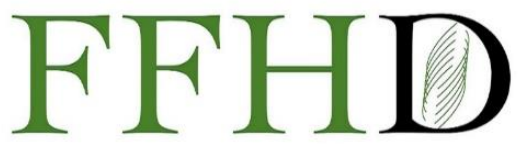

Functional Foods in Health and Disease

\title{
Inhibitory effect of black raspberry extract on AGE accumulation and degradation, and ROS production in HUVEC cells
}

\author{
Katsuaki Dan", Atsushi Takada², Yasunori Kanaho³, Yuko Kusumi ${ }^{4 *}$, Harutaka Banno ${ }^{*}$
}

${ }^{1}$ Division of Research and Development, Research Organization of Biological Activity, Crest 301, 3-44-13 Minami-ohtsuka, toshima-ku, Tokyo 170-0005, Japan; ${ }^{2}$ NPO for Natural and Healthy Skins in Environment, 2-23-4 Nakazato, Kita-ku, Tokyo 1140015, Japan; ${ }^{3}$ Department of Physiological Chemistry, Faculty of Medicine and Graduate School of Comprehensive Human Sciences, University of Tsukuba, 1-1-1 Tennodai, Tsukuba 305-8575, Japan; ${ }^{4}$ INNATUS Co. Ltd., 2-1-14 Higashi-tabata, Kita-ku, Tokyo 114-0013, Japan

*Corresponding Authors: Harutaka Banno and Yuko Kusumi, INNATUS Co. Ltd., 2-1-14 Higashi-tabata, kita-ku, Tokyo 114-0013, Japan, Tel: +81-3-3810-4468.

Submission Date: November 5 ${ }^{\text {th }}$ 2019; Acceptance Date: May 28, 2020; Publication Date: June $6^{\text {th }}, 2020$

Please Cite This Article As: Katsuaki D., Atsushi T., Tasunori K., Yuko K., Harutaka B. Inhibitory effect of black raspberry extract on AGE accumulation and degradation, and ROS production in HUVEC cells. Functional Foods in Health and Disease. 2020; 10(6): 242-253. DOI: https:/doi.org/10.31989/ffhd.v10i6.671

\begin{abstract}
Background: A critical event in age-related diseases involves the glycation of various proteins in the animal body to generate advanced glycation end products (AGEs). We have previously found that black raspberry extract (BRE) has effects on age-related diseases. From this observation, we expected that berry extracts, specifically BRE, would have positive effects on AGE-stimulated cell events that link to age-related diseases.
\end{abstract}

Objective: To discuss the potency of berry extracts against diseases attributable to the AGE-dependent changes of cellular events, in this study, we examined the effects of berry extracts on the cellular events changed upon AGE stimulation of human umbilical vein endothelial cells (HUVECs) through AGE receptors.

Methods: After HUVECs were incubated with AGE-BSA in the presence of serially diluted berry extracts, mRNA and protein levels of AGE receptors, intracellular AGE accumulation, and ROS production in the cell were determined by qRT-PCR and Western blotting, ELISA, and staining with the fluorescent probe, respectively. 
Results: Although concentration-dependent effects of berry extracts tested on mRNA levels of AGE receptors in HUVECs were not clear, mRNA level of the AGE receptor RAGE that is involved in the intracellular ROS production was increased by Blabina, which contains BRE, and the well-known anti-glycation compound aminoguanidine (AGD). In contrast, the protein expression level of RAGE was decreased by BRE and Blabina, but not by AGD. It was also found that BRE and Blabina suppressed AGE-BSA-stimulated ROS production in HUVECs. The extent of inhibition in the RAGE protein expression by BRE and Blabina was correlated well with the ROS generation measured in these samples.

Conclusions: The results obtained in this study demonstrate that BRE has the most potent inhibitory effect on ROS accumulation in the cell, probably due to the suppression in the expression level of the RAGE protein. These observations suggest that black raspberry could be a potential nutraceutical to prevent various age-related diseases.

Keywords: AGEs; RAGE; ROS; black raspberry; HUVECs.

CFFC 2020. This is an Open Access article distributed under the terms of the Creative Commons Attribution 4.0 License (http://creativecommons.org/licenses/by/4.0).

\section{INTRODUCTION}

Cellular senescence is closely related to age-related pathologies [1], since removal of senescent cells from mice has previously been shown to increase lifespan [2]. A critical event related to the cellular senescence is glycation, which is a non-enzymatic chemical reaction at amino acid residues of various proteins with sugars to generate advanced glycation end products (AGEs) [3]. AGEs play an important role in aging of the whole organism [4], therefore they are involved in a wide variety of diseases. Humans cannot avoid glycation of proteins within blood sugars because they use dietary carbohydrates as their primary energy source [5]. It has been reported that the level of AGEs in skin collagens increases with aging and is higher in diabetic patients than in healthy individuals of the same age [6]. Microvascular densities and the maturation in the skin of diabetic patients are also closely related to $A G E$ accumulation in the cell [7]. In addition, the formation and accumulation of AGEs in the cell has been shown to be involved in skin aging [8], Alzheimer's disease [9], hypertension [10], arteriosclerosis [11] and osteoporosis [12]. Therefore, the mechanism of AGE effects on cell functions has attracted attention to understanding the pathogenesis of various diseases related to $A G E s$.

Recently, two types of receptors for AGEs, one of which activates the cellular signal pathways linking to inflammation and another of which is involved in the incorporation, degradation, and elimination of AGEs, have been clarified $[13,14,15]$ (Figure 1). AGE receptors including AGE-R1 (OST-48), FEEL-1 and -2 (Stabillin-1 and -2 ), and $C D-36$ are involved in the uptake of extracellular AGEs into cells by endocytosis and their degradation. Other types of AGE receptors, such as AGE-R2 and RAGE (receptor for AGEs), activate ROS production through the stimulation of NADPH oxidase [16] (Figure 1). The best characterized AGE receptor, "RAGE," also activates the cellular signaling to stimulate the production of inflammatory cytokines [17] and acts 
as an AGE receptor in the pathogenesis of chronic obstructive pulmonary disease, cardiovascular disease, type 2 diabetes, and osteoporosis [18].

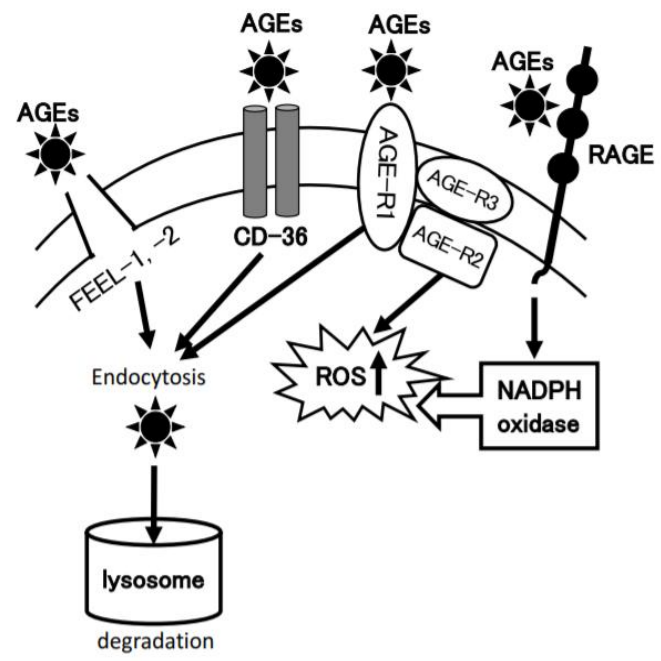

Figure 1. AGE receptors expressed in HUVEC cells and the cell signaling pathways. Receptors including AGE-R1, FEEL-1, -2, and CD-36 endocytose extracellular AGEs into cells then degrade them in the lysosome. Other AGE receptors, such as AGE-R2 and -R3, and RAGE, increase intracellular ROS either directly or indirectly through activation of NADPH oxidase.

Since AGEs and their receptor RAGE are closely related to a wide variety of diseases, glycation of proteins could be a very important target of drug development for various age-related diseases. We have previously investigated anti-aging effects of several kinds of raspberries and found that black raspberry extract (BRE) has effects on cataract, alopecia, skin whitening, and weight loss [19]. In this study, we examined the effects of berry extracts on expression levels of AGE receptors, AGE accumulation, and ROS production in the cell, and discussed the mechanisms by which berry extracts inhibit these events.

\section{MATERIALS AND METHODS}

Materials: D-Glucose, DL-glyceraldehyde, and the antiglycation compound aminoguanidine (AGD)- the well- known anti-glycation compound used as a positive control in this study- was purchased from Wako Pure Chemical Industries Ltd (Osaka, Japan). Bovine serum albumin (BSA) (Fraction V) and RAGE polyclonal antibody (Catalog Number PA5-24787) were purchased from SIGMA (St. Louis, MO, USA) and Thermo Fisher (Waltham, MA, USA), respectively. Anti-AGE-R2 (GTX101856), -RAGE (ab54741), and - $\beta$-actin antibodies (HRP-60008) were purchased from Gene Tex, abcom, and ProteinTech, respectively. AGEs ELISA Kit (STA-817) was from CELL BIOLABS.

Preparation of berry extracts: Blabina, which is a powdered formulation containing black raspberry extract (BRE) (trademark registration number 5735928), was provided in a frozen state from INNATUS Co. Fruits of black raspberries (Rubus occidentalis; BRs), blueberries (Vaccinium spp.; BBs) and raspberries (Rubus idaeus; RBs). These materials were provided in a frozen state from INNATUS Co., dissolved in $30 \%$ ethanol at $9 \mathrm{mg} / \mathrm{ml}$, and evaporated to remove ethanol [19]. Ethanol-depleted berry extracts (ca. $11.5 \mathrm{mg} / \mathrm{ml}$ ), including $B R E$, blueberry extract (BBE), and raspberry extract (RBE), were serially diluted with ultrapure water and added to human umbilical vein endothelial cells (HUVECS) (C-12203, PromoCell) in the culture medium (Endothelial Cell Growth Medium 2 Supplement Pack, C-39211: PromoCell) at a volume of $1 / 100$.

Preparation of AGE of BSA (AGE-BSA): AGE-BSA was prepared as previously described [21]. BSA (25 mg/ml) was incubated with $0.1 \mathrm{M}$ DL-glyceraldehyde in phosphate-buffed saline, $\mathrm{pH} 7.4$ (PBS), at $37^{\circ} \mathrm{C}$ for 7 days, and used in the experiments.

Cell culture: HUVECs were cultured in the culture medium at $37^{\circ} \mathrm{C}$ in a $5 \% \mathrm{CO}_{2}$ incubator. After being harvested with $0.25 \%$ trypsin and $0.1 \%$ EDTA, cells were 
seeded at $2 \times 10^{5}$ cells/well in a $35-\mathrm{mm}$ dish and cultured for $24 \mathrm{hrs}$ before use in the experiments.

Expression levels of AGE receptors: mRNA levels of AGE receptors including FEEL-1 (Stabillin-1) [22], FEEL-2 (Stabillin-2) [22], CD-36 [23], AGE-R1 (OST-48) [24], AGE-R2 (80K-H) [25], and RAGE [26] in HUVECs were measured using one-step quantitative reverse transcription-polymerase chain reaction (qRT-PCR) method. The mRNA level of glyceraldehyde-3phosphate dehydrogenase (GAPDH) was also measured as an internal control.

HUVECs were treated with AGE-BSA $(100 \mu \mathrm{g} / \mathrm{ml})$ in the presence or absence of serially diluted berry extracts at $37^{\circ} \mathrm{C}$ for $4 \mathrm{hrs}$ and total RNA was extracted from cells using TRIzol reagent (Ambion). qRT-PCR was performed in the final volume of $20 \mu \mathrm{l}$ of solution including $10 \mu$ of $2 x$ Luna Universal One-Step Reaction Mix, $1 \mu$ l of Luna WarmStart ${ }^{\circ}$ RT Enzyme Mix, $2 \mu \lambda$ (500 $\mathrm{ng})$ of total RNA solution, $1.6 \mu$ l of primer pair mix (0.4 $\mu \mathrm{M}$ for each primer), and $7.3 \mu \lambda$ of $\mathrm{H}_{2} \mathrm{O}$ under the following conditions: at $55^{\circ} \mathrm{C}$ for $10 \mathrm{~min}$ for reverse transcription and then at $95^{\circ} \mathrm{C}$ for $1 \mathrm{~min}$ for initial denaturation, followed by 45 cycles at $95^{\circ} \mathrm{C}$ for $10 \mathrm{sec}$ and at $60^{\circ} \mathrm{C}$ for $30 \mathrm{sec}$. Relative gene expression was calculated using the $\Delta \Delta \mathrm{Ct}$ method [27] and the stable expression gene, GAPDH, was used for normalization. The primers used in qRT-PCR are shown in Table 1

Quantitation of intracellular AGEs: HUVECs were stimulated with $100 \mu \mathrm{g} / \mathrm{ml}$ of AGE-BSA or BSA in the presence or absence of serially diluted berry extracts at $37^{\circ} \mathrm{C}$ for $4 \mathrm{hrs}$. The intracellular levels of AGEs, which were incorporated from outside or generated inside the cell, were then determined with the AGEs ELISA Kit (STA-817, CELL BIOLABS, INC.), according to the manufacturer's instruction. The intracellular AGE levels in HUVECs incubated with BSA and AGE-BSA were 0.7

Table 1. Primers for PCR

\begin{tabular}{|c|c|c|}
\hline Gene & Primer & References \\
\hline \multirow[t]{2}{*}{ FEEL-1 (Stabilin-1) } & Forward; AGG ACT GCC GCT ACG AAG TA & \multirow{2}{*}{22} \\
\hline & Reverse; $\quad$ CAC TGC CCT GCT GTG TGT AG & \\
\hline \multirow[t]{2}{*}{ FEEL-2 (Stabilin-2) } & Forward; TCT GAA GGC AGG TCT CAC CTA & \multirow{2}{*}{22} \\
\hline & Reverse; CTG GGG AGC AGA AAT TTT GTA & \\
\hline \multirow[t]{2}{*}{ CD-36 } & Forward; $\quad$ GAG AAC TGT TAT GGG GCT AT & \multirow{2}{*}{23} \\
\hline & Reverse; TTC AAC TGG AGA GGC AAA GG & \\
\hline \multirow[t]{2}{*}{ AGE receptor-1 } & Forward; GTG GGA AAA TGG CAC AAC TT & \multirow{2}{*}{24} \\
\hline & Reverse; CTG GCC ACG TCC CTA TTT TA & \\
\hline \multirow[t]{2}{*}{ AGE receptor-2 } & Forward; AGG GCC GTA AGG AGA GAG AG & \multirow{2}{*}{25} \\
\hline & Reverse; GTG GCG TCT GTC TGT GTG TC & \\
\hline \multirow[t]{2}{*}{ RAGE } & Forward; GAA ACT GAA CAC AGG CCG GA & \multirow{2}{*}{26} \\
\hline & Reverse; CAC GGA CTC GGT AGT TGG AC & \\
\hline \multirow[t]{2}{*}{ GAPDH } & Forward; $\quad$ AGG GCT GCT TTT AAC TCT GGT & \multirow{2}{*}{26} \\
\hline & Reverse; CCC CAC TTG ATT TTG GAG GGA & \\
\hline
\end{tabular}


$\mu \mathrm{g} / \mathrm{ml}$ (basal level) and $5.2 \mu \mathrm{g} / \mathrm{ml}$ (stimulated level) respectively. Based on these intracellular AGE levels, inhibition of AGE accumulation in the cell by berry extracts was calculated and shown as percentages.

Western blot analysis: Protein expression levels of $A G E$ receptors including $A G E-R 2$ and RAGE were also determined by Western blotting after HUVECs were treated for $24 \mathrm{hrs}$ as described above. Protein expression levels of these receptors were normalized by the actin level. HUVECs were treated as described in the section "Expression levels of AGE receptors," washed with cold PBS, scraped off, homogenized by hydrodynamic shearing with a 23-gauge needle, and centrifuged at $12,000 \times \mathrm{g}$ at $4^{\circ} \mathrm{C}$ for $20 \mathrm{~min}$. The precipitant was lysed in the lysis buffer consisting of 25 mM 4-(2-hydroxyethyl)-1-piperazineethanesulfonic acid with a $\mathrm{pH}$ of 7.1, $150 \mathrm{mM} \mathrm{NaCl}, 1 \%$ Triton-X-100, $10 \%$ glycerol, $2 \mathrm{mM}$ sodium orthovanadate, $50 \mathrm{mM}$ sodium fluoride, $10 \mathrm{mM}$ sodium pyrophosphate, $1 \%$ phosphatase inhibitor cocktails I and II and 1\% protease inhibitor cocktail. After boiling the samples at $95^{\circ} \mathrm{C}$ for $5 \mathrm{~min}, 5 \mu \mathrm{g}$ of proteins in the cell lysates were separated by sodium dodecyl sulfate-polyacrylamide gel electrophoresis (10\%) and transferred to polyvinylidene difluoride (PVDF; Millipore, Billerica, MA, USA) membranes. After being incubated with a blocking buffer consisting of $5 \%$ non-fat milk, 20 mM Tris- $\mathrm{HCl}$, pH 7.6, $150 \mathrm{mM} \mathrm{NaCl}$, and 0.1\% Tween-20, the membranes were blotted with specific antibodies to AGE receptors in the blocking buffer at $4^{\circ} \mathrm{C}$ overnight, followed by incubation with a secondary antibody for $2 \mathrm{hrs}$. The immunoreactive bands were visualized with an enhanced chemiluminescence detection system (Image Quant LAS 500, GE Healthcare Life Science) [28]. Expression levels of receptor proteins were quantified using Image J software and normalized in regard to the actin control.
Measurement of intracellular ROS production: Intracellular ROS levels were determined using the fluorescent probe CM-H2DCFDA (Molecular Probes Inc., Eugene, OR) [28]. After HUVECs were treated as described in the section "Expression levels of $A G E$ receptors," cells were washed with PBS and incubated with $1 \mu \mathrm{M}$ fluorescent probe for $60 \mathrm{~min}$ at $37^{\circ} \mathrm{C}$. Intracellular ROS levels were determined by measuring fluorescence intensity using the micro plate reader (SYNERGY/HT, BioTek, Japan). Basal intensity was 1860 \pm 163 and maximum fluorescence was $56500 \pm 237$ with arbitrary units Images were visualized under a fluorescent microscope (BZ-X710, Keyence, Osaka, Japan) and joined using its software BZ-analyzer (Keyence).

Assessment of inhibitory effects of berry extracts on in vitro AGE formation: To evaluate the anti-glycation effects of berries in vitro, a mixture of $0.5 \%$ BSA and 300 $\mathrm{mg} / \mathrm{dl}$ of D-glucose was incubated with or without berry extracts at $60^{\circ} \mathrm{C}$ for $48 \mathrm{hrs}$. Subsequently, fluorescence intensity derived from AGE-BSA formed in the reaction (370 $\mathrm{nm}$ of excitation wavelength and $440 \mathrm{~nm}$ of fluorescence wavelength) $[29,30]$ was measured using multi-mode plate reader (Synergy HTX, BioTek Japan). The basal fluorescence intensity in the presence of BSA alone and the maximal fluorescence intensity obtained in the reaction of BSA plus D-glucose were 123 and 1768, respectively. Based on these fluorescence intensities, inhibition of in vitro $A G E$ formation by berries was calculated as a percentage.

Statistical analysis: All results are presented as mean \pm SD. Statistical significance was determined using oneway analysis of variance (ANOVA) and the difference was considered statistically significant when $\mathrm{P}<0.05$.

\section{RESULTS}

Effects of berry extracts on mRNA levels of AGE receptors: To evaluate the effects of berry extracts on 
the expression of $A G E$ receptors, their mRNA levels in HUVECs were analyzed after treatment of the cell with AGE-BSA in the presence of various berry extracts (Figure 2). In mRNA, levels of AGE receptors such as FEEL-1, FEEL-2, CD-36, and AGE-R1, which are involved

(a) FEEL-1 (Stabillin-1)
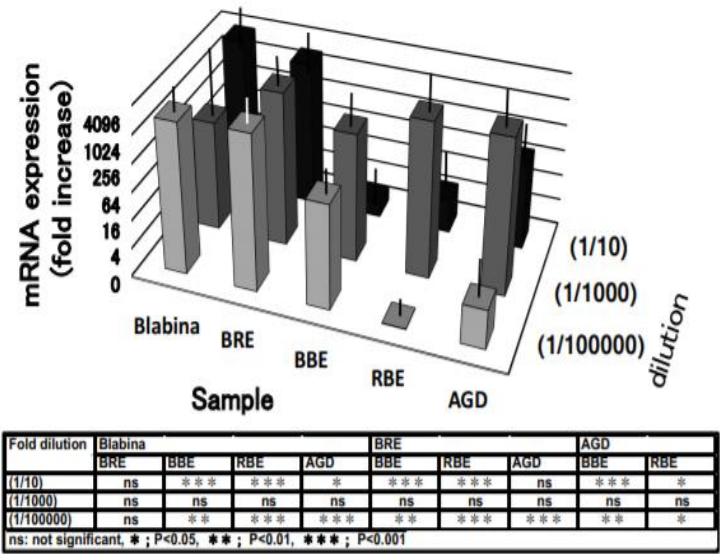

(b) FEEL-2 (Stabillin-2)
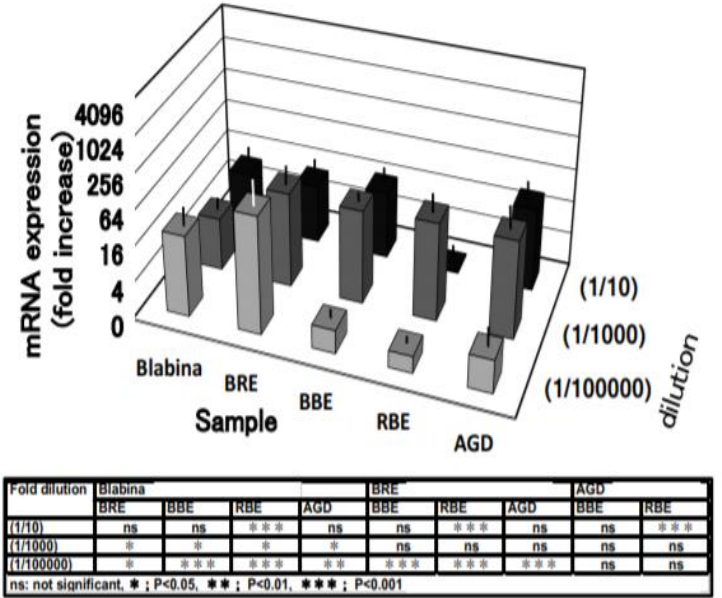

Figure $\mathbf{2}$ a, b: The mRNA expression levels of AGE receptors in HUVECs including FEEL-1 (a) and FEEL-2 (b), which are involved in glycation stress-induced $A G E$ endocytosis and degeneration.

In contrast, the mRNA level of the receptor, RAGE, which is involved in the intracellular ROS generation, was highly increased by Blabina and BRE compared with other berry extracts (Figure 2f). Although there was no in AGE incorporation and degradation, incurred neither concentration-dependent changes by berry extracts nor clear different effects among berry extracts (Figure 2a-d).

(c) $C D-36$
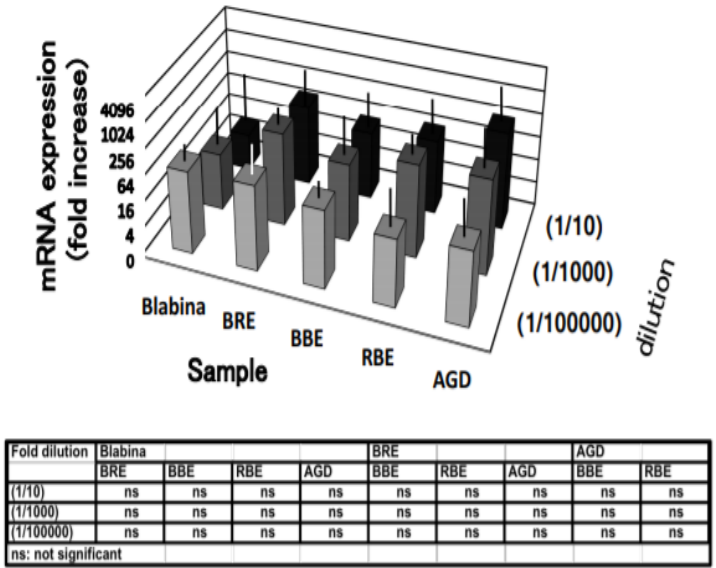

(d) AGE-R1 (OST-48)
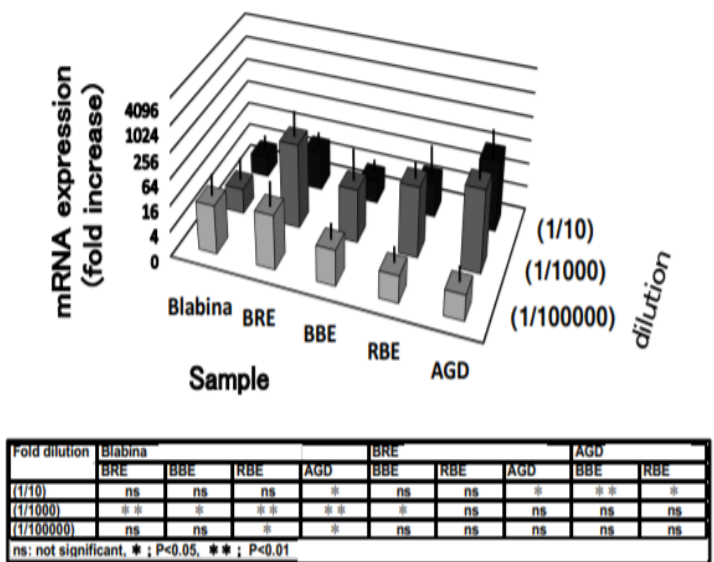

Figure 2 c, d: The mRNA expression levels of AGE receptors in HUVECs including CD-36 (c) and AGE-R1 (d), which are involved in glycation stress-induced AGE endocytosis and degeneration.

clear difference in the mRNA level of another receptor involving in ROS production, $A G E-R 2$, was observed among berry extracts (Figure 2e). The positive control 
$A G D$, Blabina, and BRE increased the mRNA level of RAGE (Figure 2f).

(e) AGE-R2 (80K-H)

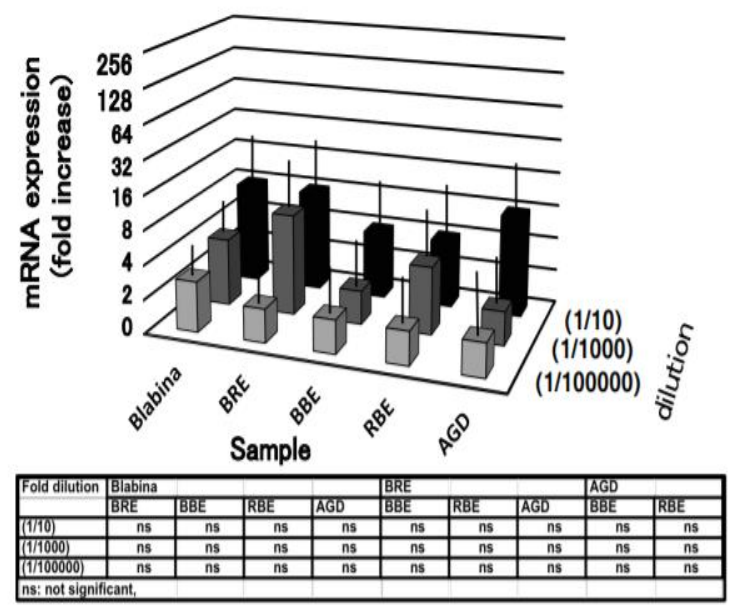

(f) RAGE
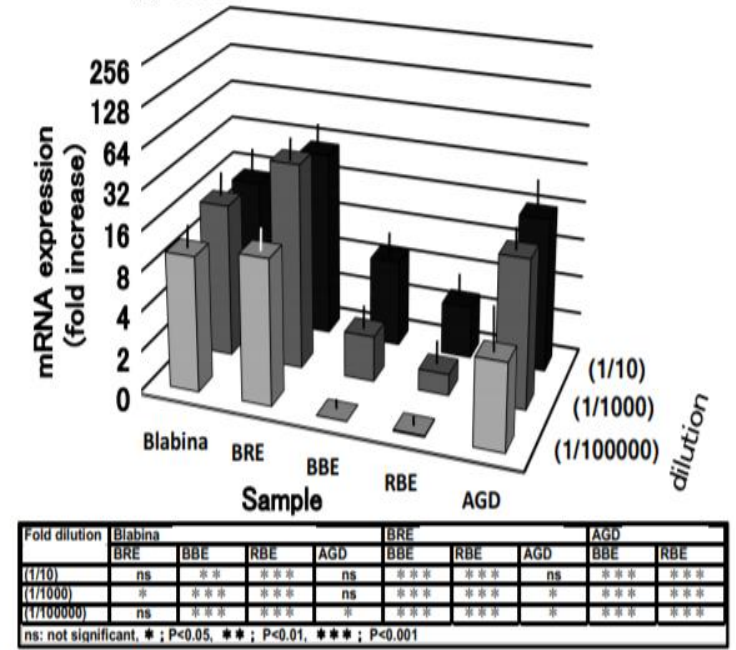

Figure $2(e)(f)$

Figure $\mathbf{2}$ e, f: The mRNA expression levels of AGE receptors in HUVECs including AGE-R2 (e) and RAGE (f), which are involved in the stimulation of ROS production by glycation stress.

Inhibition of intracellular AGE accumulation by berry extracts: Figure 3 shows the effects of berry extracts on intracellular AGE accumulation augmented by AGE-BSA stimulation of HUVECs. All berry extracts inhibited the intracellular AGE accumulation augmented by AGE-BSA in a concentration-dependent manner: about $20 \%$ inhibition by 100,000 -fold diluted berry extracts was observed. The extent of the inhibition by these berry extracts was not significantly different from that by the anti-glycation compound AGD.

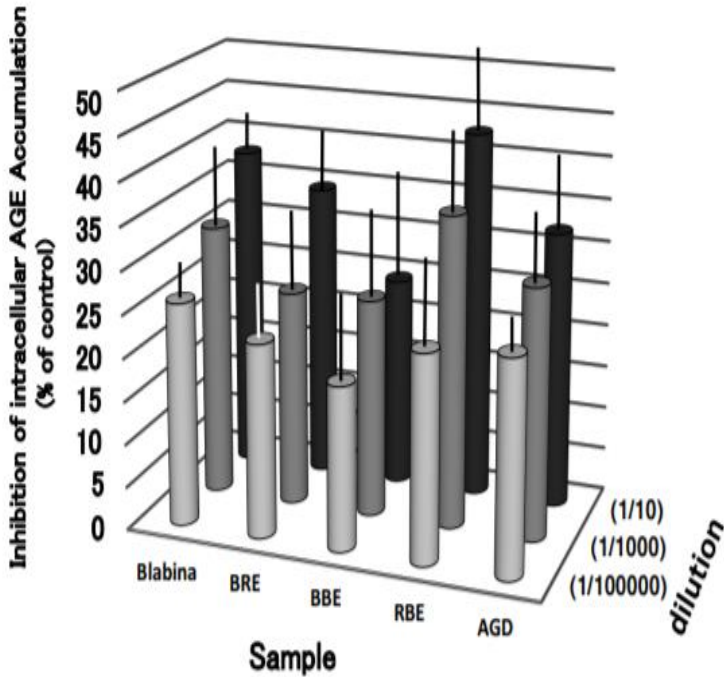

\begin{tabular}{|c|c|c|c|c|c|c|c|c|c|}
\hline Fold dilution & Blabina & & & & BRE & & & $A G D$ & \\
\hline & BRE & BBE & TRBE & AGD & BBE & RBE & AGD & BBE & RBE \\
\hline (1/10) & ns & ins & ns & ns & ns & ns & $\mathrm{ns}$ & ns & \begin{tabular}{|l}
$\mathrm{ns}$ \\
\end{tabular} \\
\hline (1/11000) & ns & n5 & ns & ns & ns & ns & $\mathrm{ns}$ & ns & $\mathrm{ns}$ \\
\hline$(1 / 1100000)$ & ns & ns & ns & ns & ns & ns & ns & $\mathrm{ns}$ & ns \\
\hline
\end{tabular}

Figure 3. Inhibition of AGE accumulation in HUVECs by berry extracts. HUVECs were treated as described in Figure 2 and intracellular AGE levels were determined as described in the Materials and Methods.

Inhibition of the protein expression level of RAGE by Blabina and BRE in HUVECs: Since Blabina and BRE increased the mRNA level of RAGE (the AGE receptor involved in the intracellular ROS production), the effects of the berry extracts on the expression level of RAGE protein in HUVECs were subsequently examined by Western blotting in comparison with that of AGE-R2 protein (Figure 4). The expression level of the AGE-R2 protein was not significantly affected by berry extracts, 
but that of the RAGE protein was evidently suppressed by Blabina and BRE.
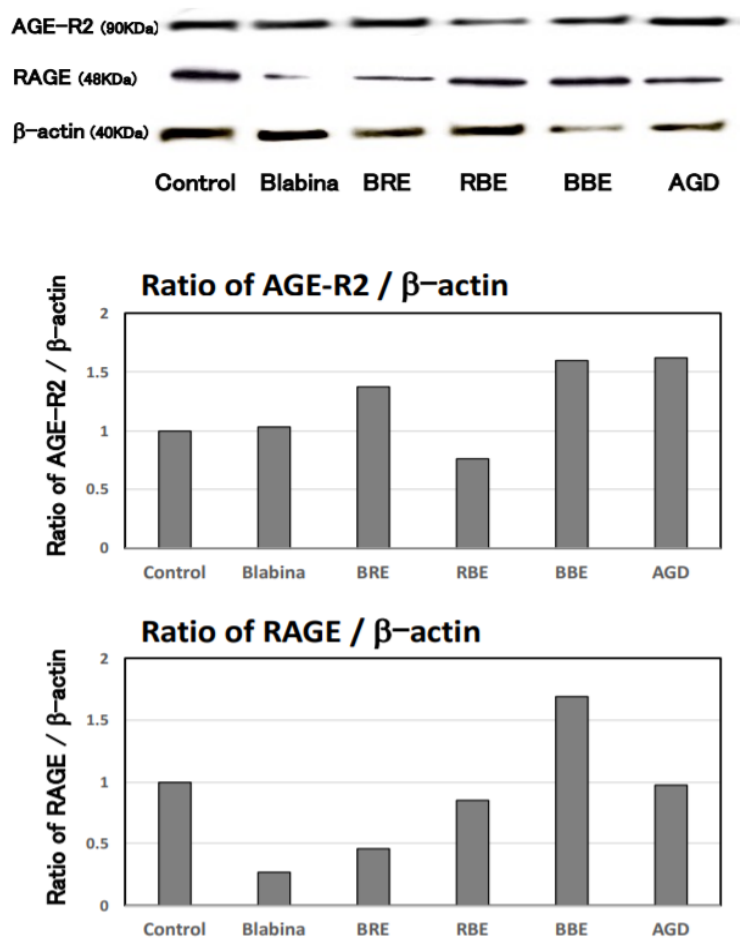

Figure 4. Protein expression levels of AGE receptors, AGE-R2, and RAGE. HUVECs were treated with AGE-BSA in the presence or absence of berry extracts as described in the section of Materials and Methods. Receptor proteins expressed were determined by Western blotting and the quantitative data for expression levels of receptor proteins was shown as the ratio of the target protein / actin.

\section{Effects of berry extracts on ROS production stimulated} by AGE-BSA in HUVEC cells: The effects of berry extracts on ROS production stimulated by AGE-BSA in HUVECs were examined using a fluorescent probe (Figure 5). All berry extracts as well as the positive control AGD inhibited ROS production stimulated by AGE-BSA in a concentration-dependent manner. It is noteworthy that the inhibition by Blabina and BRE at 1:10 dilution was markedly higher than those by other berry extracts and AGD. Furthermore, the fluorescent images shown in Figure 6 show that ROS production was inhibited by BRE. Although the inhibition of ROS production analyzed by the fluorescent image was not statistically significant, AGD tended to inhibit ROS production.

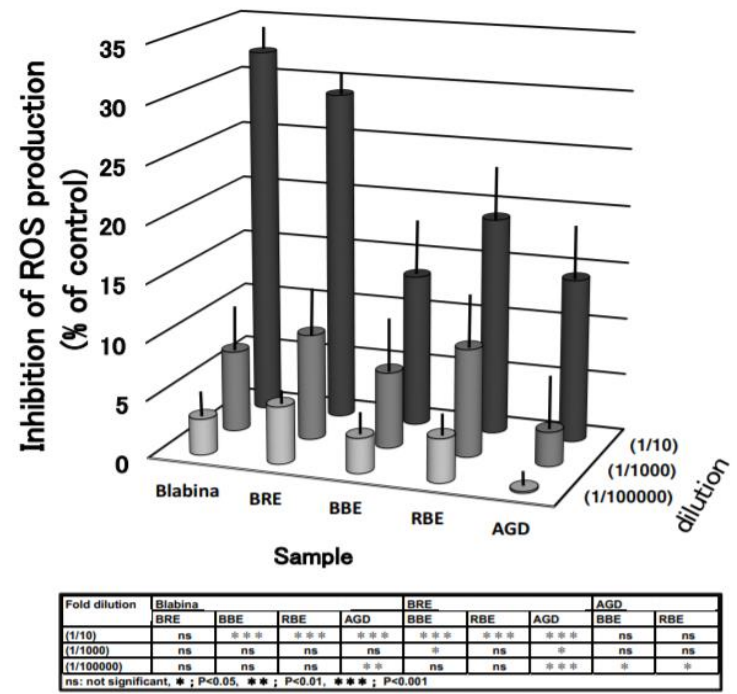

Figure 5. Inhibition of intracellular ROS production by berry extracts. HUVECs were treated as described in the section of Materials and Methods and ROS levels produced in the cell were determined using a fluorescence probe.

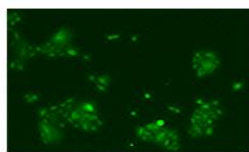

(a) BSA-AGEs alone

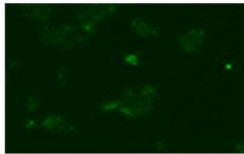

(b) BSA-AGEs

+ BRE (1/10 dilution)

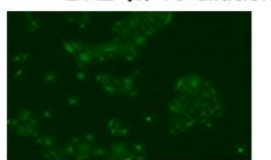

(c) BSA-AGEs

+ AGD (1/10 dilution)

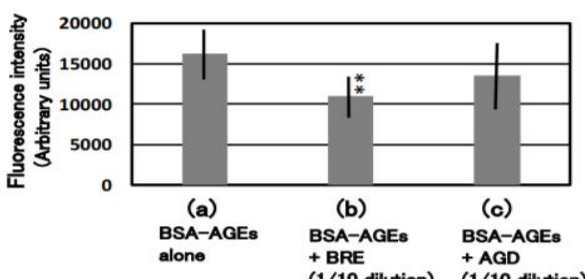

(1/10 dilution) (1/10 dilution)

Figure 6. Images for inhibition of intracellular ROS generation by BRE or AGD. After HUVECs were treated 
with AGE-BSA in the presence of BRE or AGD, ROS generated in the cell was detected using the fluorescent probe as described in the Materials and Methods. Images of ROS production were shown in the upper panels of Figure 6 . The lower panel of Figure 6 shows the quantitative data for intracellular ROS production determined as fluorescence intensity. ${ }^{* * P}<0.01$ vs AGEs alone.

Inhibition of in vitro AGE formation by berry extracts: The effects of berry extracts on the in vitro $A G E$ formation were examined as described in the Materials and Methods section (Figure 7). All berry extracts including Blabina inhibited the in vitro AGE formation in a concentration-dependent manner. Extents of inhibition by Blabina, BRE, and the positive control AGD were significantly higher than those by BBE and RBE.

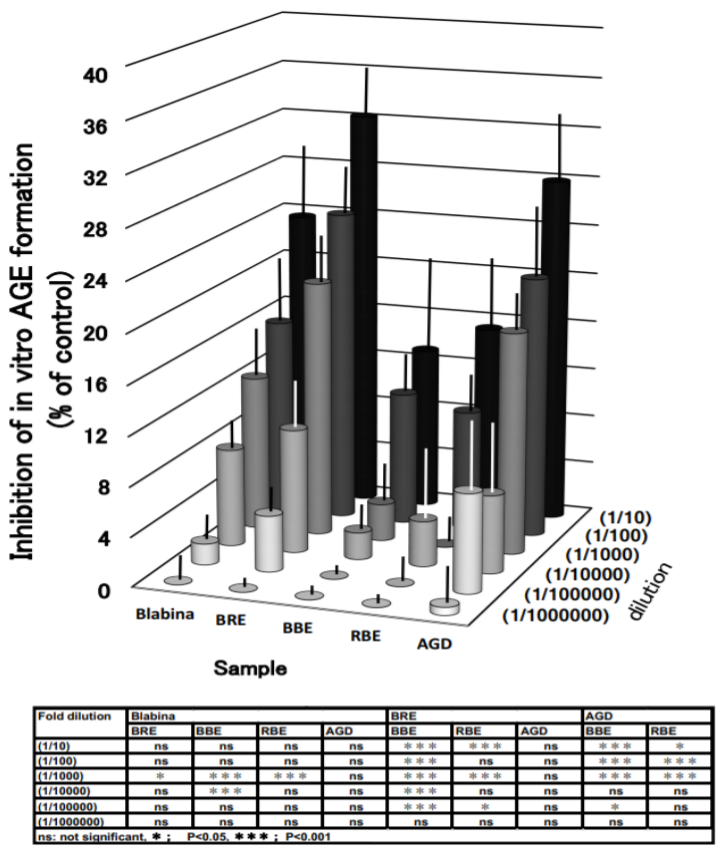

Figure 7. Inhibitory effects of berry extracts on in vitro AGE formation. The levels of AGE formed under these conditions were determined as described in the Materials and Methods section and the inhibition by berry extracts were calculated.

\section{DISCUSSION}

In this study, we demonstrate that Blabina and BRE of the already established anti-glycation compound AGD and berry extracts tested in this study have the most potent inhibitory effect on AGE-induced ROS production in HUVECs. This observation suggests that black raspberry could be a potential nutraceutical preventing various age-related diseases.

The inhibition of ROS production by BRE seems to be attributable to the suppression of RAGE protein expression in the cell as demonstrated by Western blotting probed with anti-RAGE antibody (Figure 4). This notion is supported by the fact that the extent of inhibition by BRE or AGD in ROS production was closely correlated with the RAGE protein expression (Figures 46), although AGD did not show the inhibition of ROS production when this was assessed by the fluorescence image (Figure 7). If the result showing that AGD inhibits ROS production but did not inhibit the RAGE protein expression is in fact correct, AGD may inhibit ROS production through mechanisms other than the inhibition of BRE. This issue remains to be clarified. It is also conceivable that the inhibition of ROS production by $B R E$ resulted from the prevention of $A G E$ production/accumulation in the cell. However, this is not likely since the mode of inhibition of $A G E$ production and formation in the cell and in vitro by berry extracts was not correlated with that of ROS production; all berry extracts examined in this study showed the inhibitory effect on AGE accumulation in the cell to an almost comparable extent (Figure 3), whereas inhibition of ROS production by BRE was much greater when compared with other berry extracts (Figure 5). 
Blabina and BRE suppressed the expression level of RAGE protein in the AGE-BSA-stimulated HUVECS (Figure 4). Contrasting this observation, the mRNA level of RAGE was increased by these berry samples under the same conditions (Figure 2f). This discrepancy can be accounted for by the assumption that these berry samples stimulate the production of a splicing variant of RAGE. It is known that, in addition to the full-length form of RAGE (full length RAGE: F-RAGE), two types of splicing variants of the RAGE protein are produced in the cell; one is an intracellular domain-deficient form of RAGE (C-terminally truncated RAGE: C-RAGE) which is a soluble RAGE protein to be released from the cell membrane, and another an extracellular $\mathrm{V}$ domaindeficient form (N-terminally truncated RAGE: N-RAGE) $[31,32]$. If it is true that Blabina and BRE stimulate the mRNA expression of RAGE to increase the protein expression level of C-RAGE rather than that of F-RAGE and N-RAGE, the discrepancy described above can be explained by the expression of different types of RAGE proteins in the presence of these berry samples: CRAGE cannot be detected by Western blotting of the washed cells since it is released from the cell and removed by washing the cell. It is also plausible that full length RAGE is post-translationally modified to produce these deficit forms of RAGE, e.g. proteolysis by the action of proteases. This point requires further clarification.

The components of various berry extracts have been investigated in detail [20]. It is of interest to analyze the components of BRE and investigate which component(s) of BRE is effective on the inhibition of ROS production.

\section{CONCLUSION}

In this study, we examined the effects of berry extracts on the expression levels of AGE receptors, intracellular AGE accumulation, and ROS production in HUVECs. The results demonstrate that BRE from the berry extracts examined in this study has the most potent inhibitory effect on ROS accumulation in the cell, probably due to the suppression in the expression level of the RAGE protein. These observations suggest that black raspberry could be a potential nutraceutical to prevent various age-related diseases.

Abbreviations: advanced glycation end products (AGEs), receptor for AGEs (RAGE), nicotinamide adenine dinucleotide phosphate (NADPH), reactive oxygen species (ROS), bovine serum albumin (BSA), phosphate-buffered saline (PBS), aminoguanidine (AGD), black raspberry extract (BRE), blueberry extract (BBE), raspberry extract (RBE), human umbilical vein endothelial cells (HUVECs).

Competing interests: The authors have no financial interest or conflicts of interest.

Authors' contributions: All authors contributed to this work. H. Banno, Y. Kusumi, K. Dan, and Y. Kanaho designed the research. K. Dan and A. Takada carried out the experiments and analyzed the results. All authors interpreted the results and designed the research strategy. K. Dan, A. Takada and Y. Kanaho prepared the manuscript.

\section{REFERENCES:}

1. Childs BG, Gluscevic M, Baker DJ, Laberge RM, Marquess D, Dananberg J, van Deursen JM: Senescent cells: an emerging 
target for diseases of ageing. Nat Rev Drug Discov. 2017 Oct;16(10):718-735.

2. Baker DJ, Childs BG, Durik M, Wijers ME, Sieben CJ, Zhong J, Saltness RA, Jeganathan KB, Verzosa GC, Pezeshki A, Khazaie K, Miller JD, van Deursen JM : Naturally occurring p16(Ink4a)positive cells shorten healthy lifespan. Nature. 2016 Feb $11 ; 530(7589): 184-189$

3. Goldin A, Beckman JA, Schmidt AM, Creager MA: Advanced glycation end products: sparking the development of diabetic vascular injury. Circulation. 2006 Aug;114 (6): 597-605.

4. Ajith TA, Vinodkumar P: Advanced glycation end products: Association with the pathogenesis of diseases and the current therapeutic advances. Curr Clin Pharmacol. 2016; 11(2):118 27.

5. Cerami A, Vlassara H, Brownlee M: Glucose and aging. Sci Am. 1987 May;256(5):90-6.

6. Dyer DG, Dunn JA, Thorpe SR, Bailie KE, Lyons TJ, McCance DR, Baynes JW: Accumulation of Maillard reaction products in skin collagen in diabetes and aging. J Clin Invest. 1993 Jun;91(6):2463-9.

7. Adamska A, Araszkiewicz A, Pilacinski S, Gandecka A, Grzelka A, Kowalska K, Malinska A, Nowicki M, Zozulinska-Ziolkiewicz D: Dermal microvessel density and maturity is closely associated with atherogenic dyslipidemia and accumulation of advanced glycation end products in adult patients with type 1 diabetes. Microvasc Res. 2019 Jan;121:46-51.

8. Reiser KM : Nonenzymatic glycation of collagen in aging and diabetes. Proc Soc Exp Biol Med. 1998 May;218(1):23-37.

9. Reddy VP, Obrenovich ME, Atwood CS, Perry G, Smith MA: Involvement of Maillard reactions in Alzheimer disease. Neurotox Res. 2002 May;4(3):191-209.

10. Schram MT, Schalkwijk CG, Bootsma AH, Fuller JH, Chaturvedi N, Stehouwer CD; EURODIAB Prospective Complications Study Group: Advanced glycation end products are associated with pulse pressure in type 1 diabetes: the EURODIAB Prospective Complications Study. Hypertension. 2005 Jul;46(1):232-7.
11. Brownlee $M$, Vlassara $H$, Kooney $A$, Ulrich $P$, Cerami $A$ : Aminoguanidine prevents diabetes-induced arterial wall protein cross-linking. Science. 1986 Jun 27;232(4758):1629-32.

12. Saito M, Fujii K, Soshi S, Tanaka T: Reductions in degree of mineralization and enzymatic collagen cross-links and increases in glycation-induced pentosidine in the femoral neck cortex in cases of femoral neck fracture. Osteoporos Int. 2006;17(7):986-95.

13. Goldin A, Beckman JA, Schmidt AM, et al. Advanced glycation end products: Sparking the development of diabetic vascular injury. Circulation. 2006; 114: 597-605.

14. Nagai $R$, Jinno $M$, Ichihashi $M$, et al.: Advanced glycation end products and their receptors as risk factors for aging. AntiAging Med. 2012; 9: 108-113.

15. Yamamoto $\mathrm{Y}$, Yamamoto $\mathrm{H}$ : Controlling the receptor for advanced glycation end-products to conquer diabetic vascular complications. J Diabetes Investig. 2012; 3: 107- 114

16. Bongarzone S, Savickas V, Luzi F, Gee AD: Targeting the Receptor for Advanced Glycation Endproducts (RAGE): A Medicinal Chemistry Perspective. J Med Chem. 2017 Sep 14;60(17):7213-7232.

17. Yamagishi S, Yonekura H, Yamamoto Y, Katsuno K, Sato F, Mita I, Ooka H, Satozawa N, Kawakami T, Nomura M, Yamamoto H: Advanced glycation end products-driven angiogenesis in vitro. Induction of the growth and tube formation of human microvascular endothelial cells through autocrine vascular endothelial growth factor. J Biol Chem. 1997 Mar $28 ; 272(13): 8723-30$.

18. Reynaert NL, Gopal P, Rutten EPA, Wouters EFM, Schalkwijk CG: Advanced glycation end products and their receptor in age-related, non-communicable chronic inflammatory diseases; Overview of clinical evidence and potential contributions to disease. Int J Biochem Cell Biol. 2016 Dec;81(Pt B):403-418.

19. Dan K, Takada A, Kanaho Y, Kusumi Y, Banno H. Anti-aging effects of black raspberry extract on cataract, alopecia, skin whitening, and weight loss. Functional Foods in health and Disease 2018; 8(1): 17-34. 
20. Ma H, Johnson SL, Liu W, DaSilva NA, Meschwitz S, Dain JA, Seeram NP: Evaluation of Polyphenol AnthocyaninEnriched Extracts of Blackberry, Black Raspberry, Blueberry, Cranberry, Red Raspberry, and Strawberry for Free Radical Scavenging, Reactive Carbonyl Species Trapping, AntiGlycation, Anti- $\beta$-Amyloid Aggregation, and Microglial Neuroprotective Effects. Int J Mol Sci. 2018; Feb; 19(2): 461.

21. Maeda S, Matsui T, Ojima A, Takeuchi M, Yamagishi S: Sulforaphane inhibits advanced glycation end productinduced pericyte damage by reducing expression of receptor for advanced glycation end products. Nutr Res. 2014 Sep;34(9):807-13.

22. Stoll SJ, Bartsch S, Kroll J: HOXC9 regulates formation of parachordal lymphangioplasts and the thoracic duct in zebrafish via stabilin 2. PLoS One. 2013;8(3):e58311.

23. Draude G, Lorenz RL: TGF-beta1 downregulates CD36 and scavenger receptor A but upregulates LOX-1 in human macrophages. Am J Physiol Heart Circ Physiol. 2000 Apr;278(4):H1042-8

24. Yamada Y, Ishibashi K, Ishibashi K, Bhutto IA, Tian J, Lutty GA, Handa JT: The expression of advanced glycation endproduct receptors in rpe cells associated with basaldeposits in human maculas. Exp Eye Res. 2006 May;82(5):840-8.

25. Casselmann C, Reimann A, Friedrich I, Schubert A, Silber RE, Simm A: Age-dependent expression of advanced glycation end product receptor genes in the human heart. Gerontology. 2004 May-Jun;50(3):127-34

26. Chen YH, Chen ZW, Li HM, Yan XF, Feng B: AGE/RAGE-Induced EMP Release via the NOX-Derived ROS Pathway. J Diabetes Res. 2018 Mar 18;2018:6823058

27. Kenneth $\mathrm{JL}$, Thomas DS: Analysis of relative gene expression data using real-time quantitative PCR and the 2- $\Delta \Delta \mathrm{Ct}$ method. Methods. 2001; 25(4): 402-408.

28. Yang YC, Tsai CY, Chen CL, Kuo CH, Hou CW, Cheng SY, Aneja $\mathrm{R}$, Huang $\mathrm{CY}$, Kuo WW: Pkcס Activation is Involved in ROS Mediated Mitochondrial Dysfunction and Apoptosis in Cardiomyocytes Exposed to Advanced Glycation End Products (Ages). Aging Dis. 2018 Aug 1;9(4):647-663.
29. Sell DR, Monnier VM: Structure elucidation of a senescence cross-link from human extracellular matrix. Implication of pentoses in the aging process. J Biol Chem. 1989 Dec $25 ; 264(36): 21597-602$

30. Obayashi H, Nakano K, Shigeta H, Yamaguchi M, Yoshimori K, Fukui M, Fujii M, Kitagawa Y, Nakamura N, Nakamura K, Nakazawa Y, lenaga K, Ohta M, Nishimura M, Fukui I, Kondo M: Formation of crossline as a fluorescent advanced glycation end product in vitro and in vivo. Biochem Biophys Res Commun. 1996 Sep 4;226(1):37-41.

31. Koyama $\mathrm{H}$, Yamamoto $\mathrm{H}$, Nishizawa $\mathrm{Y}$ : RAGE and soluble RAGE: potential therapeutic targets for cardiovascular diseases. Mol Med. 2007 Nov-Dec;13(11-12):625-35.

32. Lee AC, Lam JK, Shiu SW, Wong Y, Betteridge DJ, Tan KC: Serum Level of Soluble Receptor for Advanced Glycation End Products Is Associated with A Disintegrin And Metalloproteinase 10 in Type 1 Diabetes. PLoS One. 2015 Sep 1;10(9):e0137330 